\title{
O nacionalismo subtil de Estado nos governos de José Luís Rodríguez Zapatero*
}

Filipe Vasconcelos Romão'

\section{Resumo}

A relação entre os diferentes nacionalismos que actuam em Espanha geram dinâmicas conflituais que podem manifestar-se de forma violenta ou através do mero confronto democrático. Muitas vezes, o termo "nacionalismo" é utilizado para classificar as realidades periféricas catalã e basca, mas não é aplicada ao Estado central espanhol. Este, não obstante o elevado grau de descentralização do sistema político-territorial de Espanha, é parte activa nos conflitos e leva a cabo aquilo que podemos classificar como um nacionalismo de Estado. No entanto, esta actuação é matizada através de uma linguagem subtil, que varia consoante a cor partidária de quem ocupa o poder, mas que contém elementos comuns.

Este artigo percorre a história recente do nacionalismo espanhol e apresenta uma proposta de interpretação da actuação governamental do Partido Socialista Operário Espanhol (PSOE), desde 2004, à luz dos conceitos acima mencionados.

Palavras-chave: Nacionalismo. Espanha. Estado.

\section{Espanha como Estado-nação}

Em Espanha não há um consenso à volta da própria identidade nacional. Se compararmos esta situação com Portugal, onde a questão não suscita qualquer debate, verificaremos as enormes diferenças entre duas conjunturas antagónicas,

* Recebido em 30.09.2010.

Aprovado em 16.11.2010.

1 Bolseiro da Fundação para a Ciência e Tecnologia (Portugal). Aluno do Programa de Doutoramento em Política Internacional e Resolução de Conflitos, Centro de Estudos Sociais e Faculdade de Economia da Universidade de Coimbra. Contacto: vasconcelosromao@gmail.com. 
bem como o efeito de arrastamento que a ausência de consensualidade identitária tem na vida política de um Estado. Não deixa, aliás, de ser curioso que dois Estados com tão grande proximidade cultural, com uma integração económica tão profunda e que, geograficamente, partilham uma península constituam, dentro das democracias liberais ocidentais, exemplos tão diferenciados desta questão.

Não pretendendo entrar pelo discurso simplista através do qual alguns actores políticos domésticos classificam Portugal como uma nação europeia prévia ao próprio conceito de nação, não podemos deixar de concordar que este país é uma das mais antigas unidades políticas da Europa, tendo evoluído, com considerável estabilidade territorial, para Estado nacional e, posteriormente, para Estado-nação.

A situação espanhola é muito diferente. Xosé Núñez Seixas (1995, p. 493494) classifica Espanha como um "velho Estado nacional da Europa”, teoricamente datável do século XV. No entanto, não deixa de considerar paradoxal que Espanha fique "claramente retalhada", no período em que os Estados europeus se consolidam. O mesmo autor julga não ser possível afirmar a "plurinacionalidade" da Espanha de princípios do século XIX, mas sim a sua "pluralidade étnica”, em paralelo com o que terá existido em França. Não obstante, “o fracasso do processo de construção do Estado nacional espanhol" moderno terá levado à "resistência activa e consciente dos integrantes [de] grupos étnicos periféricos [...] contra o nacionalismo espanhol apercebido como unificador”.

O século XIX é marcado pelo despoletar dos nacionalismos europeus. Em Espanha, além do próprio nacionalismo espanhol, desenvolvem-se outros nacionalismos a partir de grupos étnicos periféricos, tais como o catalão, o basco e o galego (este último, em menor medida). O Estado-nação espanhol desenvolve-se, mas carregará sempre o lastro de três nacionalismos centrífugos, dois deles especialmente fortes.

A construção desta entidade política não é, assim, marcada por uma trajectória linear, acabando por perpassar uma questão fundamental, para a qual parece não haver uma resposta iniludível: terão sido as diferenças prévias a condicionar 
o processo ou terá sido uma deficiente condução deste mesmo processo que levou ao desguarnecer de alguns flancos, através dos quais se foram consolidando identidades periféricas, que acabaram por dar lugar a nacionalismos centrífugos? Não obstante, há uma afirmação que não pode ser questionada: o nacionalismo espanhol atinge o seu objectivo e, no final do século XIX, Espanha é um Estado-nação. Poderá não ser um dos exemplos mais fortes e robustos do contexto europeu, mas é reconhecida enquanto tal interna e externamente. Todavia, o percurso do nacionalismo espanhol, desde o início, está longe da placidez de alguns dos seus congéneres. Além da multiplicidade de alternativas que brotou em determinadas regiões do território que está na base do seu Estado, também teve de lidar com profundas divisões internas que, como veremos, ainda se mantêm.

Sebastián Balfour e Alejandro Quiroga (2007, p. 45- 46) consideram que, como no caso do nacionalismo francês produto do processo revolucionário, o nacionalismo espanhol também é divisível em progressista e conservador. Julgamos que a situação é ainda mais complexa, pois há uma terceira via moderada muito forte, o que acaba por pôr em evidência a existência de três grandes famílias. Os progressistas (e, mais tarde, as correntes de esquerda) vão sempre manter-se mais próximos do conceito de nacionalismo cívico, escudando-se numa certa ideia de comunidade política. Paralelamente, conservadores e moderados elaboram e exploram uma mitologia nacionalista, assente numa linha de continuidade entre os feitos levados a cabo pelos reinos hispânicos da Idade Média e o moderno Estado-nação espanhol.

\section{Guerra Civil e franquismo}

Esta divisão, devidamente matizada, arrasta-se ao longo da história contemporânea de Espanha, o que é quase equivalente a dizer que se arrasta ao longo da história de Espanha como Estado-nação. Duas interpretações nacionais de Espanha percorrem caminhos políticos paralelos até ao grande confronto que constitui a Guerra Civil travada entre 1936 e 1939. Com o fim deste conflito, Francisco Franco, general do exército e líder do chamado campo "nacional", institui um regime de extrema-direita que, num primeiro momento, está muito próximo dos 
regimes fascista e nazi. A definição oficial da identidade nacional espanhola deixa de ser objecto de qualquer tipo de discussão, passando a coincidir com a visão nacional-católica de Franco. A alternativa democrática republicana, que tivera um papel muito destacado durante a Segunda República (1931-1936) e que se aliara aos comunistas e à extrema esquerda no período da Guerra Civil, é claramente derrotada no campo de batalha e os seus partidários são eliminados fisicamente ou relegados à prisão e ao exílio.

\section{3 “Transição" e Constituição}

Os partidários de uma visão de Espanha não conservadora só recuperam o seu pleno direito a participar na política doméstica com o processo democratizador, conhecido como a "Transição", que tem início com a morte de Franco e com a subida de Juan Carlos de Borbón y Borbón à chefia de Estado, a título de rei, em Novembro de 1975. O enorme peso político das Forças Armadas espanholas e a grande identificação das suas chefias com o franquismo levam a que o novo chefe de Estado se aperceba de que qualquer movimento de abertura terá que ter origem dentro do próprio regime, o que o faz optar por um jovem ministro, Adolfo Suárez, para conduzir um processo que contará com momentos de grande turbulência.

Gradualmente, a Transição permite que as duas interpretações de Espanha voltem a emergir e a confrontar-se, desta feita num quadro de abertura democrática e com o debate a decorrer essencialmente na arena política. Os resultados são, obviamente, diferentes do produto da Guerra Civil, sendo possível chegar à redacção de um texto constitucional quase consensual, que entra em vigor em 1978.

Com efeito, na sequência das primeiras eleições livres em mais de quarenta anos, em 1977, a redacção de uma Constituição assumira a centralidade do processo legislativo. Como na esmagadora maioria dos sistema democráticos, neste texto ficou plasmado um modelo de Estado, o que implicou uma definição da sua organização territorial e a assunção de posições, por parte dos políticos, em relação aos nacionalismos centrífugos tão duramente acossados durante os anos do franquismo. $\mathrm{O}$ assumir de uma opção em relação ao Estado tinha implícita uma 
posição relativa ao que seria a própria identidade espanhola. Sebastian Balfour e Alejandro Quiroga classificam o produto deste processo como a "Espanha reinventada" e resumem-no da seguinte forma:

A Espanha reinventada da Constituição de 1978 foi uma proeza de engenharia semântica e consenso político, o que levou à difusão da ideia de que os diferentes mitos e imaginários do nacionalismo espanhol e dos nacionalismos subestatais poderiam chegar a coexistir. ${ }^{2}$ (BALFOUR; QUIROGA, 2007, p. 91).

No que concerne à definição identitária e simbólica de Espanha e à nova organização territorial do Estado, as posições alinham-se com naturalidade. Num extremo, encontrava-se a Alianza Popular (AP), composta por quadros franquistas e com uma posição abertamente nacionalista espanhola ou espanholista. No outro, os nacionalistas bascos e catalães, divididos em moderados e radicais, consoante o grau de aspiração independentista. $\mathrm{O}$ vencedor das eleições tinha sido a Unión de Centro Democrático (UCD), uma coligação heterogénea que abarcava quadros franquista moderados, comprometidos com a Transição democrática, e que, ideologicamente, abrangia desde liberais a sociais-democratas, passando por democratas-cristãos e conservadores. A constituição da UCD teve como principal objectivo servir de base à manutenção de Adolfo Suárez no poder.

Não obstante as suas inúmeras sensibilidades, a posição da coligação governante também se decanta pelo espanholismo. Numa primeira fase, os dois principais partidos de esquerda, o Partido Socialista Obrero Español (PSOE - Partido Socialista Operário Espanhol) e o Partido Comunista de España (PCE - Partido Comunista de Espanha), recentemente regressados à vida pública, manifestam uma simpatia mais acentuada por uma potencial via federal, em coerência com as linhas programáticas que mantinham durante a ditadura franquista, período em que se encontravam ilegalizados. Todavia, conforme foi evoluindo o projecto constitucional, estas posições vão-se atenuando e a esquerda espanhola acaba por

2 Tradução livre do autor. No original “La España reinventada en la Constitución de 1978 fue una proeza de ingeniería semántica y consenso político, lo que llevó a la difusión de la idea de que los diferentes mitos e imaginarios del nacionalismo español y de los nacionalismos subestatales podrían llegar a coexistir. ” (BALFOUR; QUIROGA, 2007, p. 91). 
se ver obrigada a um papel de moderador, entre o tipo de nacionalismo espanhol representado pela direita e pelo centro-direita pós-franquistas e os nacionalismos basco e catalão.

As consequências, para o nacionalismo espanhol, desta primeira etapa do novo regime democrático são, essencialmente, duas, em sentido divergente: por um lado, a direita, fruto da conotação do espanholismo com o regime ditatorial franquista, deixa de ter margem para utilizar uma terminologia explicitamente nacionalista; por outro, a esquerda também não consegue levar a cabo uma readaptação dos conceitos que estavam presentes no seu próprio discurso espanholista histórico. Cai-se, assim, numa situação de impasse dialéctico, durante o qual é evitado o recurso a símbolos e a expressões linguísticas conotáveis com a identidade nacional espanhola (NÚÑEZ SEIXAS, 2005, p. 122-123).

\section{Primeira etapa socialista no poder}

A UCD, à imagem da Transição, foi um produto de consensos. À medida que os hábitos democráticos se generalizaram e que os perigos de um regresso à ditadura ou a um novo conflito armado se afastaram, o sistema começou a funcionar com mais normalidade e o ambiente consensual foi dando lugar a disputas mais abertas. A coligação que fora a maior força política nos anos do pós-franquismo acabou por se atomizar e não passou dos 6,77\%, nas eleições gerais de $1982 .{ }^{3}$ Assim, mais depressa do que terá sido suposto por uma boa parte da direita espanhola, nessas eleições, o PSOE chegou ao poder com uma maioria absoluta avassaladora. ${ }^{4}$ Os socialistas vão manter-se no poder até 1996, vencendo quatro eleições gerais (legislativas), três delas com maioria absoluta (1982, 1986 e 1989) e umas com maioria relativa (1993).

\footnotetext{
3 Fonte: Ministério do Interior do Governo de Espanha. http://www.elecciones.mir.es/ MIR/jsp/resultados/index.htm.

4 O PSOE liderado por Felipe González obtém 48,11\% dos votos e 202 deputados num parlamento com um total de 350. Fonte: Ministério do Interior do Governo de Espanha. http://www.elecciones.mir.es/MIR/jsp/resultados/index.htm.
} 
Felipe González, incontestado líder socialista, encabeça o governo durante catorze anos. Quando chegam ao poder, e ao contrário do que seria de esperar, os jovens dirigentes socialistas não procuram lançar qualquer tipo de ponte directa com o discurso do espanholismo republicano derrotado em 1939. Em vez disso, começa a desenhar-se uma dialéctica neo-patriótica assente em três pilares: modernidade, solidariedade inter-regional e europeísmo (NÚÑEZ SEIXAS, 2007, p. 36). Ou seja, a opção é feita numa perspectiva de presente e de futuro, escamoteando quaisquer referências ao passado recente. $\mathrm{O}$ cuidado é tal que as marcas históricas assumidas passam a remeter para o período da expansão ultramarina espanhola dos séculos XV e XVI, numa estratégia de deliberado aproveitamento das celebrações do quinto centenário da descoberta da América por Cristóvão Colombo (PASTOR VERDÚ, 2007, p. 200-201; NÚÑEZ SEIXAS, 2007, p. 40).

Ao longo desta fase de governos socialistas também se procuram fundamentações teóricas para redesenhar a nova relação que se pretende com a identidade espanhola. Nestes movimentos, parece subjazer a preocupação em encontrar uma formulação nacionalista que acabe por ser aceite pela generalidade dos espanhóis. A primeira tentativa passou pela ideia de Espanha como "nação de nações". À nação espanhola caberia a componente política do conceito, com toda a carga de poder que isto acarreta, ficando as nações centrífugas remetidas à sua dimensão cultural (NÚÑEZ SEIXAS, 2007, p. 36-37). Esta linha de argumentação encaixa perfeitamente num dos preceitos constitucionais mais importantes: o que define Espanha.

Com efeito, o processo constitucional passara por uma profunda discussão em torno do nacionalismo no seu estado mais puro: os nacionalismos centrífugos basco e catalão queriam ver as respectivas identidades reconhecidas como nações, enquanto os nacionalistas espanhóis recusavam liminarmente esta opção, por entender que poderia abrir as portas ao princípio de auto-determinação, e consideravam Espanha a única entidade passível de ser assim classificada. Com múltiplas cedências, acabou por se chegar a uma solução, no mínimo, curiosa, em que se reconhece, por um lado, Espanha como única nação, mas, por outro, a existência de múltiplas "nacionalidades". Ou seja, foram utilizados dois conceitos, muito próximos um do outro, para graduar níveis de identidade dentro do mesmo Estado. Veja-se o segundo artigo constitucional: 
A Constituição fundamenta-se na indissolúvel unidade da Nação espanhola, pátria comum e indivisível de todos os espanhóis, e reconhece e garante o direito à autonomia das nacionalidades e regiões que a integram e a solidariedade entre todas. ${ }^{5}$ (CONSTITUCIÓN, 1978, p. 1).

Assim, se considerarmos "nacionalidade" como sinónimo de nação cultural e "nação" na sua acepção política, vemos como a fundamentação teórico-política vai ao encontro da realidade constitucional.

Parece, no entanto, haver uma tentativa mais forte de fundamentação de um novo nacionalismo espanhol: a adaptação do conceito de "patriotismo constitucional", gizado por Rudolf Sternberger e generalizado pelo filósofo Jürgen Habermas. Habermas pretendia encontrar novas referências para o nacionalismo alemão que ocupassem o vazio deixado aquando da queda do nazismo e da fundação da República Federal, contrapondo às tradicionais acepções românticas do nacionalismo alemão uma proposta assente nos valores que emanam das constituições democráticas e liberais dos Estados ocidentais.

O momento escolhido pelos socialistas espanhóis para esta operação não foi casual: chegou num período em que os conceitos de democracia, de modernização económica e de integração europeia já se encontram generalizados (BALFOUR; QUIROGA, 2007, p. 167). E o que poderia ser mais útil a um novo nacionalismo espanhol do que associá-lo ao bem-estar político, económico e social? Sendo que a esmagadora maioria dos símbolos nacionais democráticos (bandeira, hino, chefia de Estado) remetem, com as devidas adaptações, para o franquismo, a Constituição passa à categoria de símbolo supremo da nova prosperidade espanhola.

5 Tradução livre do autor. No original "La Constitución se fundamenta en la indisoluble unidad de la Nación española, patria común e indivisible de todos los españoles, y reconoce y garantiza el derecho a la autonomía de las nacionalidades y regiones que la integran y la solidaridad entre todas ellas." (CONSTITUCIÓN, 1978, p. 1). 


\section{0 início da plena normalização nacional: a direita democrática e conservadora chega ao poder}

A etapa de plena normalização do discurso nacionalista espanhol, quanto a nós, só tem início com a estabilização do sistema democrático que advém da primeira vitória da direita conservadora do Partido Popular (PP) numas eleições gerais. Com a chegada de José Maria Aznar ao governo, em 1996, ficam definitivamente dissipadas as naturais dúvidas que subsistiam em relação ao partido herdeiro da AP, a casa política de uma boa parte do pós-franquismo mais renitente. Sobretudo a partir de 2000, ano em que Aznar obtém a maioria absoluta que o deixa livre da dependência parlamentar dos nacionalistas moderados catalães e bascos, o PP começa a articular um discurso claramente nacionalista, abandonando o lastro constituído pelos pruridos herdados da Transição.

No âmbito desta nova etapa de nacionalismo afirmativo, Aznar também vai procurar uma versão própria do "patriotismo constitucional", a que já fizemos referência. Ao contrário dos cuidados que tinham presidido à abordagem socialista, que procurava um acolhimento transversal na sociedade, desta vez, há uma clara tentativa de colagem de um projecto nacionalista, conservador e democrático (o do Partido Popular) ao conceito. No XIV Congresso do PP, celebrado em Janeiro de 2002, Josep Piquet e Maria San Gil, simbolicamente, dois importantes dirigentes do partido na Catalunha e no País Basco, foram incumbidos da tarefa de redigir uma moção intitulada "El patriotismo constitucional del siglo XXI" (FABRÓ, 2003, p 89). Pode considerar-se que, por via deste documento, o PP oficializa o seu reencontro com algo que há muito procura: a compatibilização entre o seu programa nacionalista espanhol e uma linguagem adequada à realidade espanhola democrática.

No entanto, de acordo com Montse Mateo Fabró, há diferenças fundamentais entre Habermas e os populares:

- A exigência por parte do PP de uma vinculação do cidadão não só aos princípios democráticos, mas também à sua visão específica de Espanha, que tem o seu corolário na exclusão de todos os nacionalismo centrífugos, por ser contrários à constituição; 
- O facto de os populares se recusarem e reflectir acerca do franquismo e a condená-lo explicitamente.

\section{Encerrando o ciclo de normalização identitária: o nacionalismo espanhol subtil do novo poder socialista}

A inesperada vitória do PSOE nas eleições gerais de 2004, apenas três dias depois dos atentados islamistas de 11 de Março, vem consolidar a etapa de normalização aberta pela vitória da direita. José Luís Rodríguez Zapatero, ao longo dos quatro anos que estivera na oposição, já demonstrara querer conduzir a esquerda à superação dos impasses da Transição, à imagem do que Aznar fizera com a direita. Ao nível identitário, o documento mais relevante do período prévio à chegada ao poder intitula-se "La España Plural: La España Constitucional, la España Unida, la España en Positivo" e emana da secretaria-geral do partido, sendo apresentado em conselho territorial em Agosto de 2003. No texto, é reafirmada a fidelidade à Constituição e ao Estado autonómico, mas actualiza-se este apoio com a inserção do conceito de "Espanha plural" e com a defesa da revisão do modelo territorial (FAJARDO SPÍNOLA, 2009, p. 171-172).

Mesmo antes de regressar ao governo, os socialistas já estavam, assim, a demonstrar alguma margem de manobra para propor políticas alternativas ao nacionalismo de direita do PP. No entanto, é a partir do poder que lançam uma agenda de esquerda, livre das restrições anteriores. Num momento em que as Forças Armadas se encontram profissionalizadas, que Espanha se encontra plenamente integrada na União Europeia e que o franquismo começa a ser uma recordação distante ou inexistente para grande parte da sociedade, os socialistas apercebem-se de que a ausência de tutelas lhes permite desenvolver um programa de modernização social que, apesar de poder gerar uma considerável resistência conservadora, tem boas possibilidades de prosperar.

Do ponto de vista identitário, a agenda de Zapatero pode ser analisada de duas formas: através da atitude que o poder central mantém em relação aos nacionalismos centrífugos; e através de uma interpretação do computo geral das suas políticas, à luz do projecto nacional espanhol. Se considerarmos que o nacionalismo não se limita ao 
próprio discurso e que tem uma forte componente de acção, poderemos aperceber-nos de que a implementação de medidas aparentemente distantes da problemática identitária podem espelhar esta mesma problemática ou ser uma consequência sua.

Existem acções de cunho nacionalista que, embora mais discretas, eventualmente, assumem uma natureza mais transcendente. Por exemplo, uma expressão tantas vezes enunciada como é o caso da 'defesa do regular funcionamento das instituições' pode consubstanciar um acto que materialize a coincidência entre uma identidade nacional e um Estado. Se estas instituições se referirem a órgãos de poder estatais e servirem um objectivo de continuidade desta entidade nos mesmos moldes, constitui um acto de defesa de uma identidade no poder. As políticas activas de defesa e manutenção da integridade e soberania de um Estado, levadas a cabo a partir do governo central, democraticamente instituído, por um determinado grupo de representantes eleitos, no caso o PSOE, não podem, assim, deixar de ser classificadas como nacionalismo, não obstante o seu carácter mais discreto do que no caso dos nacionalismos reivindicativos ou dos expansionistas.

Passamos agora a enunciar três exemplos daquelas que consideramos ser as três faces da nova abordagem nacionalista de esquerda: uma mais tradicional e directamente ligada à questão identitária, a luta contra o independentismo violento basco; uma com uma componente histórico-ideológica, a lei de memória histórica; e, finalmente, uma representativa das novas questões civilizacionais, o casamento entre pessoas do mesmo sexo. Cada um destes casos constitui uma peça do complexo puzzle de um modelo de Espanha proposto.

No primeiro caso, podemos observar que numa política emblematicamente tão relevante, para Espanha, em termos de nacionalismo, como a do combate ao independentismo basco radical e violento, o actual governo, depois de uma fase de tentativa de resolução do conflito por via negocial, prossegue uma linha muito activa de manutenção da integridade do Estado. O êxito desta política é indubitável e é atingido sem necessidade de recorrer a qualquer discurso de exaltação patriótica, o que parece fazer prova de que um nacionalismo não precisa de se auto-afirmar dialecticamente para o ser. A dialéctica centra-se no combate aos "criminosos terroristas", algo que congrega apoios generalizados na sociedade. 
No segundo caso, também sem assumir qualquer género de linguagem nostálgica do republicanismo, Zapatero não se limitou a contornar as restrições herdadas da Transição e atacou de frente o franquismo: através de uma lei de memória histórica, aprovada em Outubro de 2007, entre outras coisas, foi aberta a porta à retirada da grande maioria de símbolos públicos de exaltação à ditadura; foi fomentada a identificação das vítimas do anterior regime assassinadas e enterradas em fossas comuns; e foi concedida a nacionalidade a filhos e netos de exilados políticos. Com esta linha de actuação, comprova-se que o não assumir de um discurso abertamente declarativo já não se prende com os receios da Transição, parecendo inerente a uma nova filosofia e respondendo a uma estratégia deliberada.

Finalmente, o caso das questões civilizacionais aparenta ter como função dar um conteúdo ideológico pós-material ao novo projecto. Quase vinte anos depois da queda da única alternativa ao modelo económico liberal, a esquerda precisou de encontrar novas bandeiras diferenciadoras e uma delas foi a defesa de um novo quadro de direitos civis que, entre outros elementos, comporta o casamento entre pessoas do mesmo sexo. Zapatero, para surpresa dos sectores mais conservadores, conseguiu levar Espanha, país de longa tradição católica, a ser um dos pioneiros nesta matéria, a tal ponto de a direita não se comprometer com a revogação da medida num hipotético futuro governo. O líder socialista pretende, assim, alterar os valores aos quais a imagem de Espanha é associada.

O combate ao projecto independentista violento basco, do ponto de vista identitário, e a memória histórica e o casamento entre pessoas do mesmo sexo, do ponto de vista ideológico, são ilustrativos de uma nova acepção espanholista que parece estar a ser gizada e que corresponde a uma alternativa de esquerda às cartas que a direita já tinha posto na mesa nos oito anos de governo de Aznar.

É assim que chegamos ao que consideramos ser um nacionalismo subtil: um nacionalismo que nunca se afirma enquanto tal e cuja imagem de marca é uma tentativa deliberada em centrar o discurso e, através deste, as atenções da cidadania noutras questões (por exemplo, nas políticas sociais e económicas). Mesmo quando o tema central é um problema de disputa entre nacionalismos, como no caso do conflito basco, é evitada qualquer marca de exaltação dialéctica. Em vez 
disso, o êxito das forças policiais no combate ao terrorismo independentista basco da organização Euskadi Ta Askatasuna (ETA) é sempre interpretado pelo governo em termos de sucesso na luta contra o crime e nunca em termos de vitória política sobre outra identidade.

\section{Conclusão: o regresso a um modelo de duas alternativas}

Actualmente, a política espanhola encontra-se profundamente bipolarizada. O antagonismo e a animosidade têm marcado as relações entre PP e PSOE desde que este último regressou ao governo. Poder-se-á considerar que o extremar de posições se deve a uma derrota nunca digerida dos populares, que perderam as eleições de 2004 no contexto da grande consternação e confusão que se seguiu aos atentados do 11 de Março. Também se poderão assacar responsabilidades a um PSOE que não soube gerir a própria vitória e que nunca se esforçou por alcançar consensos com o principal partido da oposição em políticas de Estado. No entanto, o que para nós parece evidente é que o quadro de alternativas democráticas ficou, definitivamente, clarificado.

Desde a sua origem, o nacionalismo espanhol foi marcado por uma profunda divisão ideológica. Isto conduziu a que, em Espanha, ser de esquerda e de direita não se limite a uma diferenciação entre opções políticas económicas e sociais: também acarreta duas alternativas identitárias. Esta dualidade foi escamoteada por mais de duas décadas, em consequência da Transição, pacto estabelecido para instituir o regime democrático num país traumatizado pela memória recente de um sangrento conflito armado civil e por uma ditadura de quarenta anos.

É assim que acaba por se chegar à última versão da alternativa entre duas Espanhas, agora num contexto democrático-liberal e de plena inserção no processo de integração europeia. Por um lado, uma Espanha conservadora, com um discurso de marcado orgulho nacional e de afirmação enquanto potência histórica que procura recuperar o passado glorioso; por outro, uma Espanha progressista, que se centra numa actualização da sua imagem e na superação dos fantasmas do passado e que pretende estar na vanguarda de direitos pós-materiais. No entanto, 
pretende continuar a ser Espanha e isto é uma marca indelével, talvez a mais importante, de qualquer nacionalismo: a manutenção do Estado-nação.

\section{El nacionalismo sutil de Estado en los gobiernos de José Luís Rodríguez Zapatero}

\section{Resumen}

La relación entre los diversos nacionalismos que están presentes en España generan dinámicas de conflicto que se pueden manifestar de forma violenta o por vía de la simples confrontación democrática. Muchas veces, la expresión "nacionalismo" es utilizada para calificar las realidades periféricas catalana y vasca, pero no es aplicada al Estado central español. No obstante el alto grado de descentralización de su sistema político territorial, España es parte activa en los conflictos y se expresa por lo que podríamos calificar como un nacionalismo de Estado. Su actuación es matizada por vía de un lenguaje sutil, que puede variar en función de la ideología de quienes están en el poder, pero que tiene elementos comunes.

Este artículo traza la ruta de la historia reciente del nacionalismo español y presenta una propuesta de interpretación de la actuación gubernamental del Partido Socialista Obrero Español (PSOE) desde 2004, con base en los conceptos arriba mencionados.

Palabras-clave: Nacionalismo. España. Estado.

\section{Referências}

BALFOUR, Sebastian; QUIROGA, Alejandro. España reinventada. Barcelona: Ediciones Península, 2007.

CONSTITUCIÓN ESPAÑOLA. Madrid. 1977. Disponible en:< http://www.lamoncloa.es/Espana/LeyFundamental/index.htm >. Acesso en: 30 de Set. de 2010. 
FABRÓ, Montse Mateo. La idea de España a finales del s. XX: El nacionalismo español desde la transición. 2003. Disponible en:< http://www.scribd.com/ doc/7387118/Mateo-Fabro-Montse-La-Idea-de-Espana-a-Finales-Del-Siglo-XX >. Acesso en: 28 set. 2010.

FAJARDO SPÍNOLA, Luís. Hacia otro modelo de Estado? Pamplona: Thomson Reuters, 2009.

LA ESPAÑA plural: la España constitucional, la España unida, la España en positivo. Resolução do Conselho Territorial do PSOE. Santillana del Mar. 2003. Disponible en: <http://www.psoe.es/ambito/actualidad/docs/ index. do?id=12209\&action=View $>$. Acesso em: 4 de Março de 2010.

NÚÑEZ SEIXAS, Xosé M. Os nacionalismos na Espanha contemporânea: umas perspectiva histórica e algumas hipóteses para o presente. Análise Social. v. 30, p. 489-526. 1995.

NÚÑEZ SEIXAS, Xosé M. From Nacional-Catholic nostalgia to constitucional patriotism: conservative Spanish nationalism since the early 1990s. In: BALFOUR, Sebastián (Ed.) The politics of contemporary Spain. Abingdon: Routledge, 2005. p. 121-145.

NÚÑEZ SEIXAS, Xosé M. Patriotas y demócratas: sobre el discurso naconalista español después de Franco (1975-2007). 2007. Disponible en: < http://amarauna. org/uztariz/pdf/artikuluak/aldizkaria2003.pdf >. Acesso em: 2 mar. 2010.

PASTOR VERDU, Jaime. La izquierda de ámbito estatal. Entre el 'patriotismo constitucional' español y el federalismo plurinacional. In: TAIBO, Carlos (Ed.) Nacionalismo español: esencias, memoria y instituciones. Madrid: Los Libros de la Catarata, 2007. p. 193-212. 


\section{Para publicar na revista Universitas}

Relações Internacionais, entre no endereço eletrônico www.publicacoesacademicas.uniceub.br. Observe as normas de publicação, facilitando e agilizando o trabalho de edição. 